\title{
Limited sensitivity analysis of ARAIM availability for LPV-200 over Australia using real data
}

\author{
A. El-Mowafy ${ }^{1}$ and C. Yang $^{2}$ \\ 1. Dept. of Spatial Sciences, Curtin University, Australia \\ Email: a.el-mowafy@curtin.edu.au \\ 2. Limitless Surveys, ycyc8828596@gmail.com
}

Current availability of advanced Receiver Autonomous Integrity Monitoring (ARAIM) for LPV-200 in aviation is experimentally investigated using real navigation data and GPS measurements collected at 60 stations across Australia. ARAIM algorithm and fault probabilities were first discussed. Availability sensitivity analysis due to changes in the elevation mask angle and the error model parameters URA, URE, and nominal biases for integrity and accuracy used for computation of the protection level is presented. It is shown that incorporation of other GNSS constellation with GPS in ARAIM is needed to achieve LPV-200 Australia wide. The inclusion of BeiDou with GPS at two tests sites in Western and Eastern Australia demonstrates the promising potential of achieving this goal.

Keywords: ARAIM; LPV-200; GNSS; BeiDou; Integrity Monitoring.

\section{Introduction}

When Global Navigation Satellite Systems (GNSS) are used in aviation, system integrity must be assured (ICAO, 2009). Integrity refers to the ability of the system to provide timely warning to users when the system is not suitable for navigation. Therefore, GNSS receivers used in aviation are typically supported with integrity monitoring process, such as Receiver Autonomous Integrity Monitoring (RAIM). RAIM also provides real-time protection of users against satellite faults that are not being flagged by the ground control (Parkinson and Axelrad 1988; Lee 1998). To verify positioning integrity, the Navigation Sensor Error (NSE) must be within the navigation requirements in both the lateral and vertical dimensions, where requirements on vertical navigation are more demanding as the pilot relies on the navigation devices to estimate height above ground for landing.

With the modernization of GPS and its integration with other constellations, the new civilian signals such as L5 and E5a allow receivers to cancel the ionosphere delay, the largest GNSS error source (Ivanov et al., 2011; Jin et al., 2013 and 2015), and the increased number of satellites results in improving user geometry. This has led to consider the use of RAIM for vertical guidance. The new algorithms for this purpose have been labelled Advanced RAIM (ARAIM). Several ARAIM methods have been discussed in the literature (GEAS 2010; Blanch et al. 2012; Lee 2012). The present focus on ARAIM is its use for the Localizer Performance with Vertical guidance down to 200 feet (LPV-200). LPV-200 procedures have requirements in four performance metrics, namely: availability, accuracy, continuity and integrity of the service.

In Australia, there is a clear need for development of the ARAIM algorithms to enable the aircraft avionics to mitigate faults and to assure failsafe navigation due to the absence of a Satellite-Based Augmentation System (SBAS). In addition, Ground-Based Augmentation Systems (GBAS) have very limited coverage where they are being developed in a five phases plan starting with a pilot GBAS at Sydney International Airport (Airservices Australia 2014). 
Some ARAIM algorithms have been presented for integration of GLONASS or Galileo with GPS (Ene et al. 2007; Choi et al. 2012; Rippl et al. 2014). In addition, preliminary incorporation of Beidou in ARAIM is presented in El-Mowafy 2013; Liu and Zhu 2014; and El-Mowafy 2014b. Most of ARAIM studies tested the method using simulated data on a global scale, typically using a grid of two-degrees interval (approximately $200 \mathrm{~km}$ ), such as in Blanch et al. 2010; Wu et al. 2013; Lin and Jan 2014, where "predicted" ARAIM availability was analysed.

In this contribution, we focus on exploring ARAIM availability for LPV-200 procedures over Australia and restrict attention to the use of real navigation data and measurements, mainly GPS, at 60 continuously operational stations selected at main locations across Australia, therefore, providing information of "actual" ARAIM availability. The use of real data allows for use of actual URA received within the satellite navigation files, and determination of vertical position error $(V P E)$ at stations of known positions. $V P E$ can be computed as the difference between the station known vertical position and the computed one from observations. Thus, we can evaluate whether $V P E$ is bounded by the vertical protection level $(V P L)$ and it does not exceed the vertical alert level $(V A L)$. If $V P E>V P L$ this is considered a misleading information event and if $V P E>V A L$ this signifies a hazardously misleading information event.

A summary of the applied ARAIM algorithm is first presented and possible GPS fault probabilities used in the model are discussed. In addition, experimental analysis of the impact of changes in error model parameters and the elevation mask angle on the availability of ARAIM is performed. Finally, improvement of ARAIM availability is demonstrated when adding BeiDou measurements to GPS measurements.

\section{GPS fault probabilities}

In ARAIM computations, overbounding of observation errors are classified into two levels: one for integrity evaluation and another affects continuity and accuracy. Integrity can affect safety-of-life directly; therefore, an overbound of the worst case error is needed. Continuity is the probability that the specified system performance will be maintained for the duration of a phase of operation (RTCA 2004). Therefore, continuity risk, defined here as the probability of an unpredicted loss of service during an approach, is a combination of contributions from unpredicted satellite signal outages, false integrity alerts, true integrity alerts, and other causes (GEAS 2010).

In ARAIM, it is important to define possible fault probability levels since they have a direct impact on method performance investigated here. The United States has made performance commitments for GPS from which the fault-probabilities were set. The Standard Positioning Service - Performance Standard (SPS PS) of GPS has provided assurances that there would not be more than three major service failures per year for the GPS constellation as a whole. This confirms with the historical records of occurrence of GPS signal faults (GEAS 2010), which show the ability to remove faulted signals in less than one hour (Walter et al. 2013). Hence, the onset probability $\left(P_{a-p r i o r i}\right)$ is taken equivalent to $1 \times 10^{-5}$ per satellite per hour $(\approx 3 /[31$ sat $\times 365$ day $\times 24 \mathrm{hr}])$, approximated to per approach. The probability that there is a fault on one specific GPS satellite and not on any of the other GPS satellites being used, denoted as $P_{\text {sat,GPS }}$, can be approximated by using $P_{a-p r i o r i}$. The total integrity budget taken as the probability of hazardously misleading information $\left(\operatorname{Pr}\{\mathrm{HMI}\}_{\mathrm{v}}\right)$ is the probability that the 
true vertical position lies over the error bound determined by user (Blanch et al, 2010). $\operatorname{Pr}\{\mathrm{HMI}\}_{\mathrm{v}}$ is taken $1 \times 10^{-7}$ per approach derived from the International Civil Aviation Organization (ICAO) standards (ICAO 2009). The false alert probability for vertical guidance is taken equal $4 \times 10^{-6}$ per 15 -second interval, which was derived from the ICAO continuity risk requirement. The allowable false alert probability per sample is also taken the same as the probability per 15-second interval at $4 \times 10^{-6}$. A major service failure is assumed in the event that the instantaneous signal-in-space (SIS) user equivalent range error (UERE) > 4.42 the broadcast user range accuracy $(U R A)$ for GPS block II satellites (corresponds to a significance level $10^{-5}$ ) and $U E R E>5.73 \times U R A$ for GPS block III satellites (a significance level $10^{-7}$ ) when the satellite is set "healthy" without a timely alert being issued (Shively 2009). The URA accounts for clock and ephemeris errors in the absence of faults and is used to evaluate integrity monitoring. It is disseminated to users through the navigation message.

Common-mode faults can be mainly attributed to the data used by the Master Control Station (MCS), which may be caused by the use of erroneous prediction of Earth orientation parameters; erroneous phase centre location estimation at monitor stations; uploading wrong information to the satellites or erroneous values of various constants used by the MCS. At the moment, the probability of common mode GPS satellite faults $\left(P_{\text {const }}\right)$ is extremely low but it can be assumed $10^{-4}$ to reflect a situation where a constellation-wide fault could appear and the constellation service provider takes several hours to flag the fault (EU-U.S. 2015). Since a consistency check of ARAIM for a common-mode fault is not feasible for a single system, it is only applied when assimilating multiple systems, such as when integrating GPS and BeiDou as will be shown later.

\section{Computations of ARAIM availability}

In this section, ARAIM process used in this study is summarised. A flowchart of the procedure is illustrated in Figure 1. It starts with fault detection and exclusion (FDE), where faulty satellites are detected and excluded from the navigation solution for safety reasons. Next, VPL is computed epoch-by-epoch. Availability of ARAIM is considered the fraction of time when integrity service is supported. For vertical positioning, ARAIM availability is checked by testing that VPL is bounded by a selected vertical alert limit (VAL) (GEAS 2010).

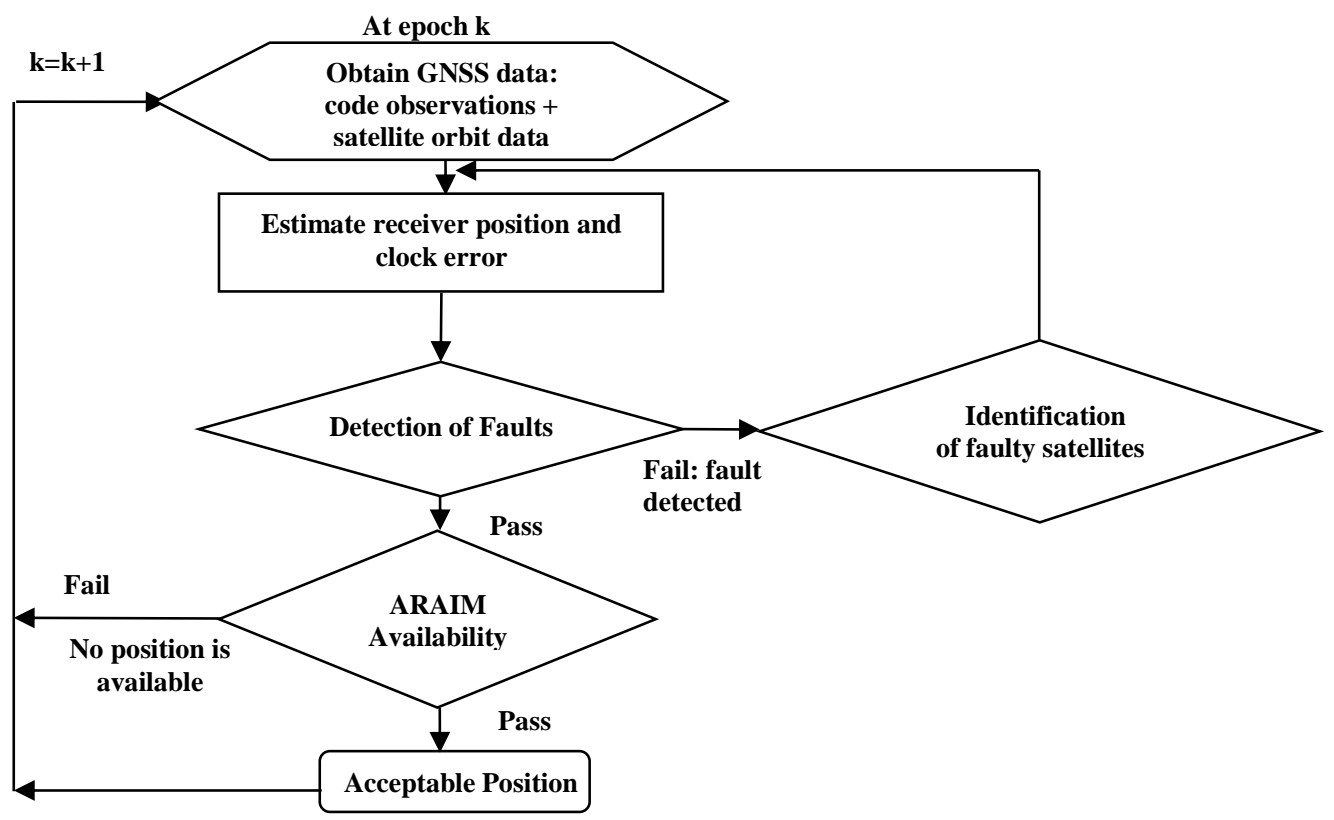

Figure 1. ARAIM Methodology 
In this research, the Multiple Hypothesis Solution Separation (MHSS) method is applied. The MHSS evaluates the different fault modes given the specified probabilities of faults and determines the optimal probability of missed detection (Blanch et al. 2012; Joerger and Pervan 2014). The linearized fault-free GNSS code measurement model using all satellites in view can be expressed as:

$$
y=G x+\varepsilon
$$

where $y$ is the measurement vector, taken as the difference between the observed code pseudo ranges and the calculated ones from the approximate values of the coordinates. The first order ionosphere delay is eliminated by using ionosphere-free linear combination of code measurements. $x$ denotes the difference between the final and approximate values of the unknown parameters, which include the three dimensional position components and receiver clock error. $\varepsilon$ is the nominal noise, which is characterised by a stochastic component and a bias component (Blanch et al. 2014b). The direction cosine matrix $G$ provides the transformation between the observation domain and the position domain. For the $n^{\text {th }}$ satellite, the corresponding row $G_{n}$ reads:

$$
G_{n}=\left[\begin{array}{llll}
-\cos \theta_{n} \sin \alpha_{n} & -\cos \theta_{n} \cos \alpha_{n} & -\sin \theta_{n} & 1
\end{array}\right]
$$

where $\theta_{n}$ and $\alpha_{n}$ denote the elevation angle and the azimuth for satellite $n$, determined from the broadcast satellite ephemeris and approximate receiver location. When introducing fault modes, the large error (fault) state $\nabla_{f}$ is added to the observation model, which becomes:

$$
y=G x+G_{f} \nabla_{f}+\varepsilon
$$

where the number of columns of the matrix $G_{f}$ equals the number of errors (faults) considered in $\nabla_{f}$. To detect faults, this number should not be larger than the degrees of freedom. Each column of $G_{f}$ has a one in the index corresponding to the satellite assumed to be affected and zeros elsewhere. A position error bound is created for each fault mode by computing a position solution unaffected by the fault, computing an error bound around this solution and accounting for the difference between all-in-view position solution and the fault tolerant position (Blanch et al. 2013).

The least square solution of the unknown parameters for all satellites in view reads:

$$
\hat{x}=\left(G^{T} W_{U R A} G\right)^{-1} G^{T} W_{U R A} y=S \times y
$$

where $S=\left(G^{T} W_{U R A} G\right)^{-1} G^{T} W_{U R A}$, and $W_{U R A}$ is a diagonal weight matrix of the measurement vector $y$ computed using the broadcast $U R A$ and the assumed standard deviations for multipath, receiver noise $\left(\sigma_{n, u s e r}\right)$ and troposphere delay $\left(\sigma_{n, \text { tropo }}\right)$. The $n^{\text {th }}$ diagonal element of $W_{U R A}$ is (GEAS 2010):

$$
W_{U R A_{n}}=\frac{1}{U R A_{n}^{2}+\sigma_{n, \text { user }}^{2}+\sigma_{n, \text { tropo }}^{2}}
$$

For a fault mode $i$, which has one or multiple faulty satellites, $S_{i}$ is:

$$
S_{i}=\left(\left(A_{i} G\right)^{T} W\left(A_{i} G\right)\right)^{-1}\left(A_{i} G\right)^{T} W
$$


where $A_{i}$ is a reformed identity matrix of size $m$ such that the diagonal elements corresponding to the suspected faulty satellites are replaced by zero. The position estimate corresponding to mode $i$ is:

$$
\hat{x}_{i}=S_{i} y
$$

The threshold corresponding to this fault mode, denoted as $T_{i}$, for the vertical position (indicated by the subscript 3) is (Blanch et al. 2013):

$$
T_{i}=K_{f f d, i} \times \sigma_{d V, i}+\left|\left(S-S_{i}\right)_{3}\right| \times \text { bias }_{a c c}
$$

where $\left|\left(S-S_{i}\right)_{3}\right|$ is the sum of elements of the third row of $\left(S-S_{i}\right) . K_{f f d, i}$ is a scalar used to satisfy the false alert probability, computed from the inverse of the complement of the onesided standard normal cumulative distribution function. $\sigma_{d v, i}$ is the standard deviation computed from:

$$
\sigma_{d v, i}=\sqrt{e_{3}^{T}\left(S-S_{i}\right)^{T} W_{U R E}^{-1}\left(S-S_{i}\right) e_{3}}
$$

where $e_{3}$ denotes a vector whose $3^{\text {rd }}$ entry is one and zero elsewhere, $W_{U R E}$ is a diagonal weight matrix structured similar to $W_{U R A}$ by replacing the $U R A$ by the user range error (URE) in Equation 5. URE is the non-integrity-assured standard deviation of the range component of clock and ephemeris errors and is used to evaluate accuracy and continuity performance. The nominal bias $\left(\right.$ bias $\left._{a c c}\right)$ is assumed to bound possible remaining small biases when assessing accuracy. For all considered fault modes, a fault detection test is applied, where a fault is suspected when (Blanch et al. 2013):

$$
\left|\hat{x}_{i}-\hat{x}\right|_{3}>T_{i}
$$

and faulty satellites are excluded. When the test passes for all $i$ modes, VPL is computed.

The LPV-200 requirements described in the GNSS standards and recommended practices (SARPs) of ICAO that can be used for evaluation of ARAIM availability are:

1) $V P L \leq V A L$ where $V A L=35 \mathrm{~m}$ for LPV -200

2) Effective Monitor Threshold $(E M T)=\operatorname{Max}\left\{T_{i}\right\} \leq 15 \mathrm{~m}$

3) $95 \%$ vertical accuracy $\leq 4 \mathrm{~m}$

4) $\left(1-10^{-7}\right)$ fault-free vertical accuracy $\leq 10 \mathrm{~m}$.

The first condition is sufficient to practically consider ARAIM available (GEAS 2010). To achieve LPV-200, ARAIM availability is assumed to be above $99.5 \%$ (this number has not been finalised yet). In this contribution, $V P L$ is computed following the baseline method presented in EU-U.S. WG 2012; and Blanch et al. 2014a. $V P L$ is taken as the $\max \left\{V P L_{o}\right.$, $\left.\max \left(V P L_{i}\right)\right\}$, where $V P L_{o}$ is the $V P L$ for the fault-free full set case where:

$$
V P L_{o}=\text { Gaussian term }+ \text { Bias overbound }=K_{m d, 0} \times \sigma_{v, 0}+\left|S_{3}\right| \times \text { bias }_{\text {int }}
$$

For fault mode $i, V P L_{i}$ is:

$$
V P L_{i}=T_{i}+K_{m d, i} \times \sigma_{v, i}+\left|S_{i_{3}}\right| \times \text { bias }_{\text {int }}
$$


with $\sigma_{v, 0}=\sqrt{e_{3}^{T} S^{T} W_{U R A}^{-1} S e_{3}}$ and $\sigma_{v, i}=\sqrt{e_{3}^{T} S_{i}^{T} W_{U R A}^{-1} S_{i} e_{3}} . K_{m d, 0}, K_{m d, i}$ are scalar factors that are used to satisfy the miss-detection probabilities and are computed from the inverse of the complement of the one-sided standard normal cumulative distribution function (Blanch et al., 2014b). bias int $_{\text {is }}$ ise assumed maximum nominal bias used to bound potential non-zero mean error distributions for integrity evaluation.

\section{ARAIM availability over Australia and sensitivity analysis for changes in the error model parameters}

In this section, ARAIM availability is investigated across Australia and the effect of changes in the elevation mask angle as well as main error model parameters (URA, URE, $\boldsymbol{b i a s}_{\text {int }}$ and $\boldsymbol{b i a s}_{\text {acc }}$ ) on ARAIM availability is experimentally studied. The computed VPE at the known test stations were checked against VPL.

\subsection{Test Description}

ARAIM availability was investigated over Australia using real multi-frequency data from 60 GNSS stations including 14 International GNSS Service (IGS) stations and 46 AuScope Continuously Operating Reference Stations (CORS) (AuScope is a company that serves the geodetic infrastructure in Australia). Figure 2 shows the geographic distribution of these stations. These stations have good distribution in the populated areas in Australia where airports are located, which represent our main interest when studying ARAIM. The gap areas are either remote areas, or desert of very low population. Data of January 2014 with a sample rate of 30 seconds was used to show ARAIM availability. Ionosphere-free linear combination of L1 and L2 GPS observations was used in processing. The real GNSS data were tested epoch by epoch, where availability is presented as the percentage of epochs when ARAIM service is available, i.e. $V P L<V A L$. As mentioned earlier, compared with the use of simulated data implemented in other studies, real data allows for use of actual URA included in the satellite navigation files, application of the FDE step, and determination of vertical position error $(V P E)$ at the test stations, where VPE was computed as the difference between stations' computed vertical positions from observations and the known ones. At the 60 test sites, when ARAIM availability requirement was met, we checked that $V P E$ was less than $V P L$. Although years of data are needed to check integrity at the target level of $\operatorname{Pr}\{\mathrm{HMI}\}_{\mathrm{v}} \leq 10^{-7}$, our main objective was to evaluate ARAIM availability, not integrity, where GPS satellite geometry, for instance, repeats daily with a shift $\approx 4$ minutes. Checking bounding $V P E$ by $V P L$ and $V P E$ $<V A L$ can give some indication about the expected performance of the used method.

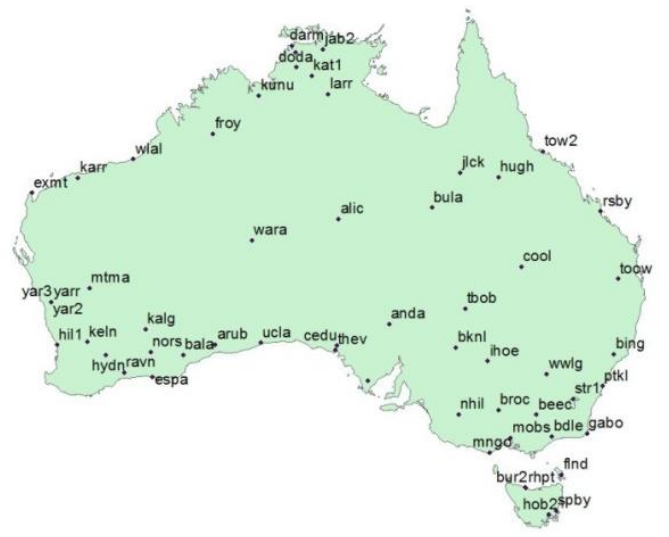

Figure 2. Distribution of data sites 
Currently, only URA is broadcast in the navigation files and URE, bias acc $_{\text {are not }}$ available but are proposed to be provided (in addition to $\mathrm{P}_{\text {sat }}$ and $\mathrm{P}_{\text {const }}$ ) through an Integrity Support Message (ISM). Monthly ISM is suggested for what is proposed as 'offline ARAIM' and hourly ISM for 'online ARAIM' (EU-U.S. WG-C RAIM 2015). To show the impact of each parameter separately, base values of other parameters were used when testing this parameter and corresponding changes in the ARAIM availability were analysed.

\subsection{Impact of the URA Changes on ARAIM Availability}

The URA is computed as the standard deviation of the overbounding normal distribution for signal-in-space errors and is associated with accuracy of computation of satellite orbit and clock errors. URA is provided in the navigation message through an index; each index corresponds to a specific range. The maximum value in each range is used for ARAIM evaluation. Currently, the most common index for $U R A$ is 0 , which gives a maximum value $2.4 \mathrm{~m}$. The $U R A$ is expected to improve in the future with the deployment of modernised satellites, the use of better processing algorithms and the use of CNAV. For instance, the expected $U R A$ for GPS block III may reach $0.75 \mathrm{~m}$.

The effect of reducing $U R A$ to $1 \mathrm{~m}$, as a conservative future value, is first compared with the use of current broadcast $U R A$ values, where the same GPS data was processed in the two cases. Figures 3 and 4 illustrate the geographic distribution of availability across Australia for the two situations, and Figure 5 depicts their histograms. The used values for URE, bias int and bias ${ }_{a c c}$ were $0.25 \mathrm{~m}, 0.5 \mathrm{~m}$ and $0.1 \mathrm{~m}$, respectively. The availability is presented as contoured zones drawn from ARAIM availability computed at a $1^{\circ}$ grid using real navigation files in addition to the availability computed at the 60 test stations. Figures 3 and 4 show that the central area of Queensland has the best ARAIM availability, whereas southern Victoria and Tasmania have the worst availability. For the latter, ARAIM availability significantly increases from 0.880 0.885 to 0.959 0.963 with the $U R A$ change from current values to $1 \mathrm{~m}$. For the 60 test stations, only 20 stations had ARAIM availability within the range 0.98 0.999 with current $U R A$, whereas there were 53 stations (88\%) when $U R A$ equals $1 \mathrm{~m}$.
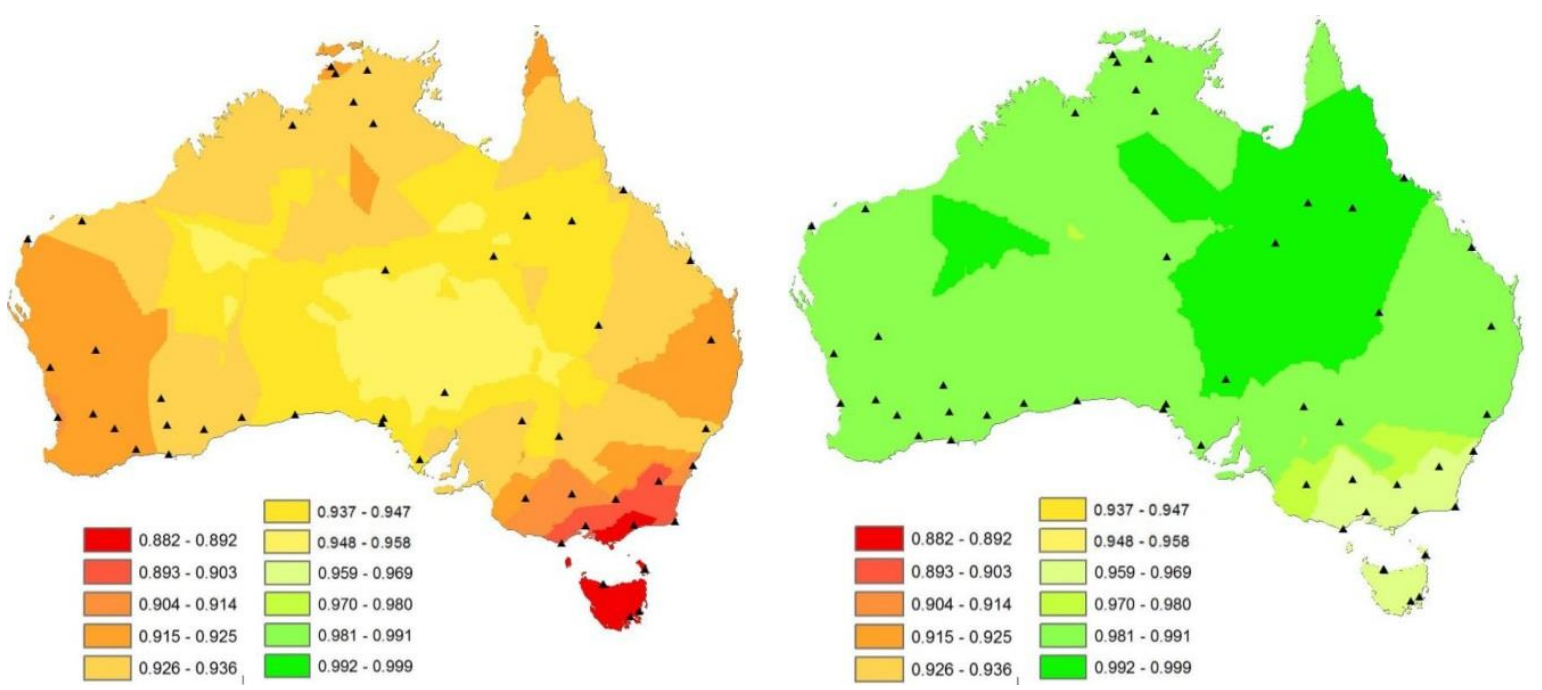

Figure 3. Availability using current broadcast $U R A$ Figure 4. Availability using $U R A=1 \mathrm{~m}$ 


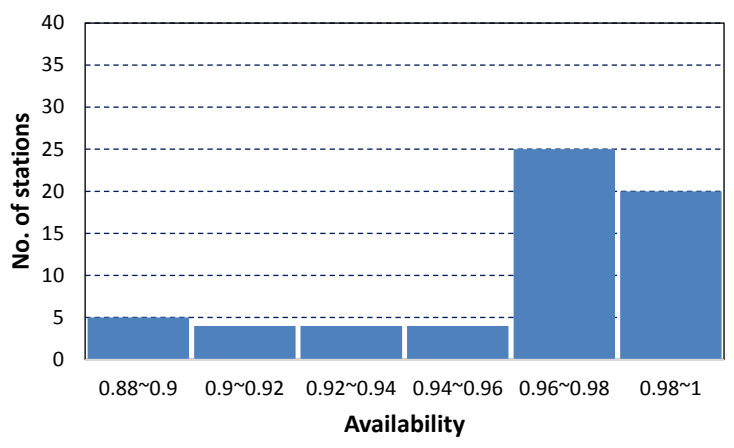

(a)

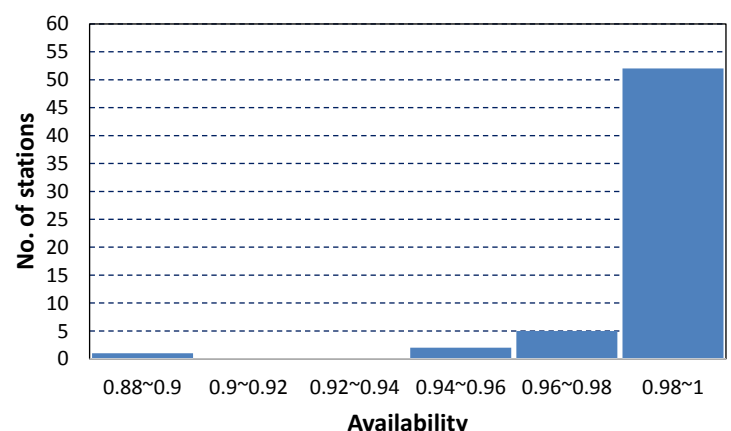

(b)

Figure 5. Frequency of availability using current $U R A$ (a) and using $U R A=1 \mathrm{~m}$ (b)

The geographic changes in ARAIM availability can be explained by changes in the number of satellites and their geometry (represented for instance by the Dilution of Precision - DOP or the VPL) observed at different locations. This is depicted in Figure 6 for two example sites: hugh, which has high availability of 0.995 , and rhpt, which has low availability of 0.956 , when using $U R A$ of $1 \mathrm{~m}$ and an elevation mask angle of $5^{\circ}$. As the figure shows the number of observed satellites at hugh (Figure 6.a) was more than 7 with PDOP less than 3 all the time, resulting in high availability. On the other hand, the number of observed satellites at rhpt (Figure 6.b) was less than 6 during some periods with a PDOP higher than 5, which led to unavailability of ARAIM at these periods, resulting in a reduction of the overall availability.

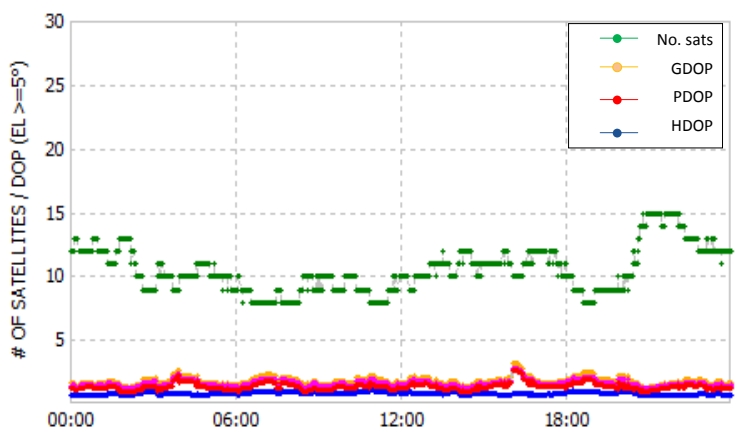

(a)

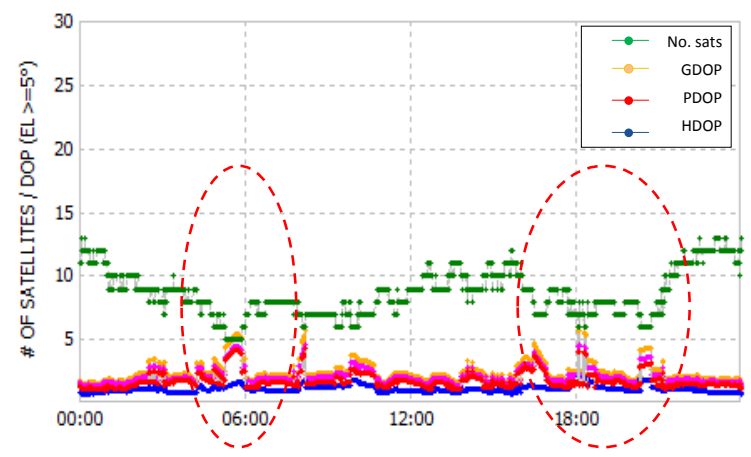

(b)

Figure 6. Satellite number and G/P/HDOP values for stations hugh (a) and $\operatorname{rhpt~(b)~}$

In theory, lower $U R A$ provides better ARAIM availability since it gives smaller $V P L$ which in turn assists in meeting the availability requirement (i.e. $V P L<V A L=35 \mathrm{~m}$ ). This is experimentally demonstrated through this study. Table 1 gives the average values of the ARAIM availability when using current broadcast $U R A$ and when using $U R A$ equals $1 \mathrm{~m}$ for all points (grid points and 60 stations). The table shows that availability has improved by $7.6 \%$ between the two cases. The average values of EMT and $\left(1-10^{-7}\right)$ accuracy estimate are given in the table for the two cases under consideration. In general the accuracy conditions: $95 \%$ vertical accuracy $\leq 4 \mathrm{~m}$ and $\left(1-10^{-7}\right)$ fault-free vertical accuracy $\leq 10 \mathrm{~m}$, as well as $E M T$ $\leq 15 \mathrm{~m}$ were met whenever the availability condition $V P L<V A L$ was met. 
Table 1: Change of average value of availability using $U R A=1 \mathrm{~m}$ and current broadcast

\begin{tabular}{ccccc}
\hline URA & $\begin{array}{c}\text { Availability } \\
V P L<V A L\end{array}$ & $\begin{array}{c}\text { Average 95\% } \\
\text { accuracy } \leq 4 \mathrm{~m}\end{array}$ & $\begin{array}{l}\text { Average }\left(1-10^{-7}\right) \\
\text { accuracy } \leq 10 \mathrm{~m}\end{array}$ & $\begin{array}{l}\text { Average } \\
\text { EMT }\end{array}$ \\
\hline Current broadcast & 0.861 & $2.87(\mathrm{~m})$ & $7.79(\mathrm{~m})$ & $6.63(\mathrm{~m})$ \\
\hline $1 \mathrm{~m}$ & 0.927 & $2.59(\mathrm{~m})$ & $7.05(\mathrm{~m})$ & $5.92(\mathrm{~m})$ \\
\hline
\end{tabular}

Figure 7 shows the average change of ARAIM availability for the 60 test sites when URA changes with a selected step of $0.2 \mathrm{~m}$ ( $20 \%$ of the expected future value of $1 \mathrm{~m})$, when reprocessing the same data discussed above. The $U R A$ ranged between $1 \mathrm{~m}$ and $3.4 \mathrm{~m}$, which is the maximum value for a $U R A$ index of 1 . The plot shows that ARAIM availability experienced a decline as the $U R A$ increases. When $U R A$ is between $1 \mathrm{~m}$ and $2.4 \mathrm{~m}$, the availability decreases almost linearly with a slope of $2.5 \%$; however, after $2.4 \mathrm{~m}$, a sharp decline can be seen with the increase in $U R A$ values.

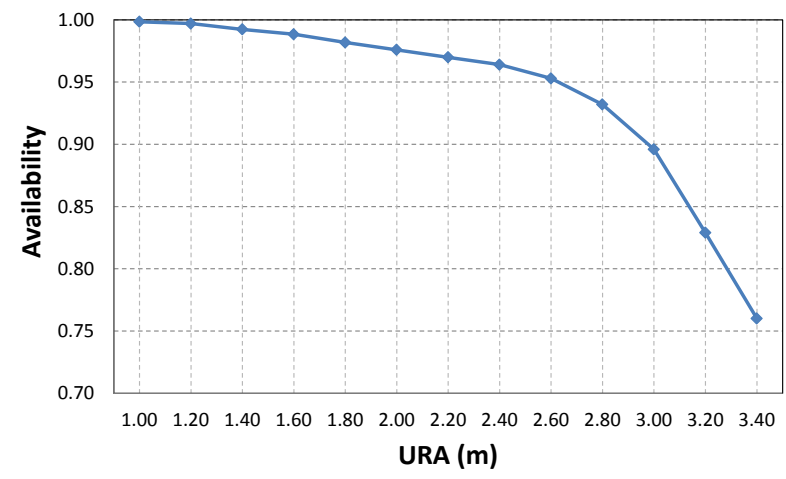

Figure 7. Change of ARAIM availability as a function of change of URA

\subsection{Impact of the elevation mask angle}

The elevation mask angle directly affects the satellite number in view and the constellation geometry, and accordingly influences ARAIM availability and positioning results. Hence, elevation mask angle needs to be carefully selected. If the mask angle is set too high, available satellite number might be less than what is required for ARAIM algorithm; and if the mask angle is set too low, low elevation satellites will be included which tend to suffer more from multipath and atmospheric errors, resulting in large errors. In our tests, the elevation mask angles of $5^{\circ}$ and $10^{\circ}$ were tested. The former is the minimum elevation angle to be used according to IS-GPS-200H (2013) and was utilised in several ARAIM studies, such as Rippl et al. 2011; EU-U.S. WG-C RAIM 2012; and Joseph 2014. To account for small banking of aircraft, the mask angle may be set to $10^{\circ}$. Figures 8 and 9 illustrate a comparison of ARAIM availabilities across Australia for the test period using elevation mask angle of $5^{\circ}$ and $10^{\circ}$. The availability is again presented as contoured zones drawn from ARAIM availability computed at a $1^{\circ}$ grid using real navigation files in addition to the availability computed at the 60 test stations. The used values for URA, URE, bias int and bias ${ }_{a c c}$ were $1 \mathrm{~m}, 0.25 \mathrm{~m}, 0.5 \mathrm{~m}$ and $0.1 \mathrm{~m}$, respectively. 


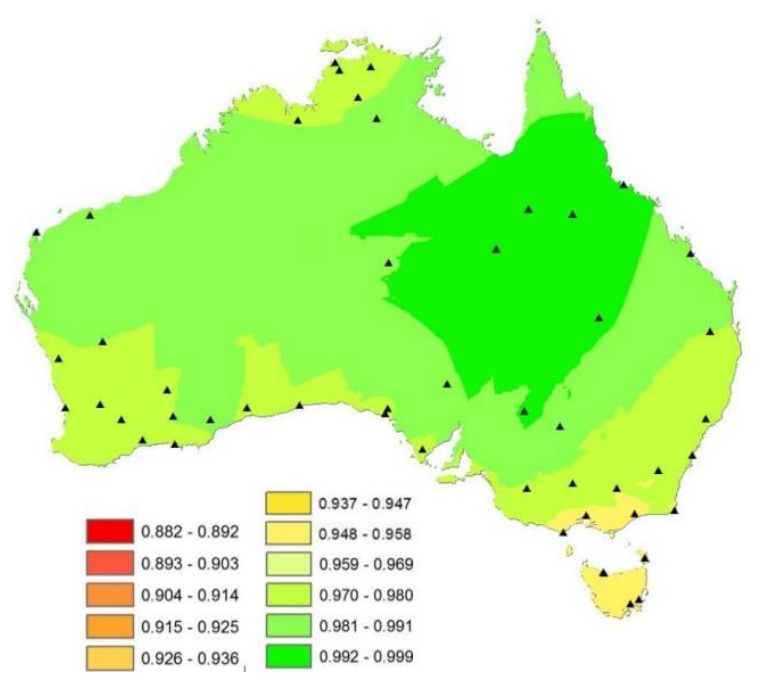

Figure 8. Availability with $5^{\circ}$ mask angle

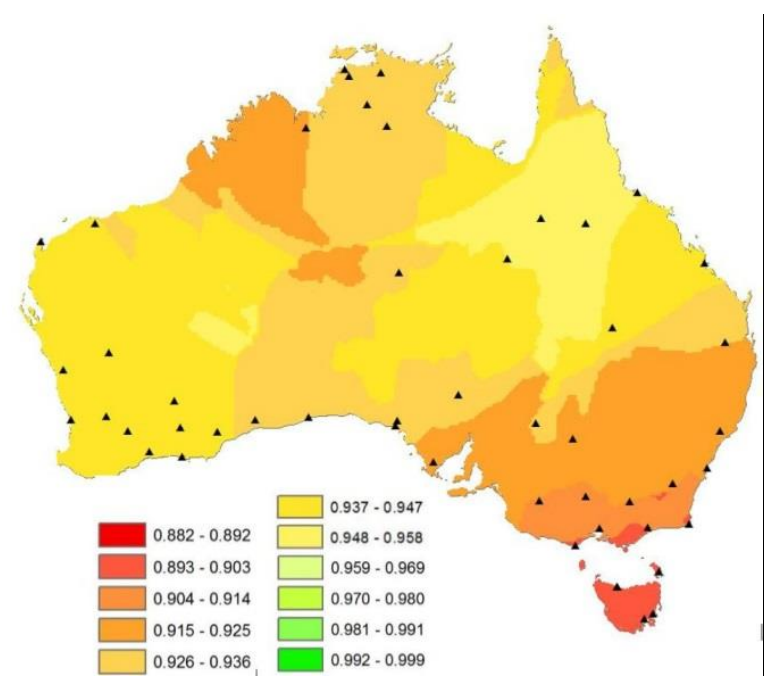

Figure 9. Availability with $10^{\circ}$ mask angle

The mask angle affects number of observed satellites as shown in Figure 10, which illustrates the time series of the number of observed satellites and DOP values using a mask angle of $5^{\circ}$ (Figure 10.a) and $10^{\circ}$ (Figure 10.b) at station Exmt. As Figure 10 depicts, when the mask angle was raised from $5^{\circ}$ to $10^{\circ}$, a significant drop of the number of observed satellites with a significant increase in PDOP took place. This explains the increase of $V P L$ and accordingly the decline in ARAIM availability when comparing the Figures 8 and 9. Table 2 summarises the average results where the average ARAIM availability decreased by almost $5.18 \%$ when the elevation mask angle was raised from $5^{\circ}$ to $10^{\circ}$.

Table 2: Change of average values of availability using different mask angles

\begin{tabular}{cc}
\hline Elevation angle & Availability \\
\hline $5^{\circ}$ & 0.927 \\
$10^{\circ}$ & 0.879 \\
$\%$ of change & $-5.18 \%$ \\
\hline
\end{tabular}

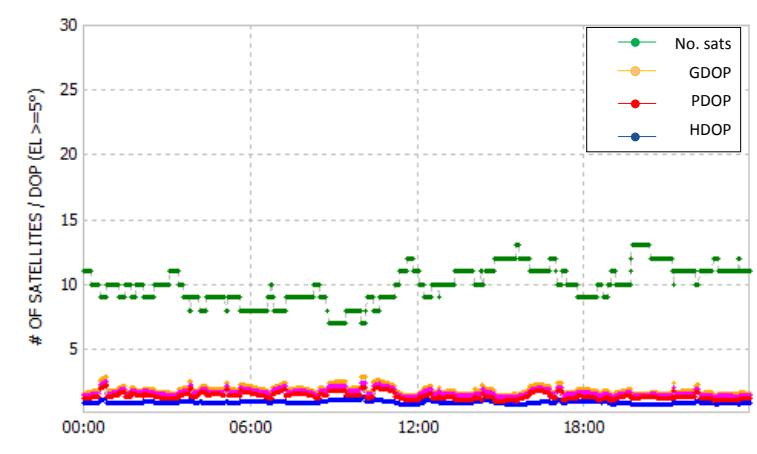

(a)

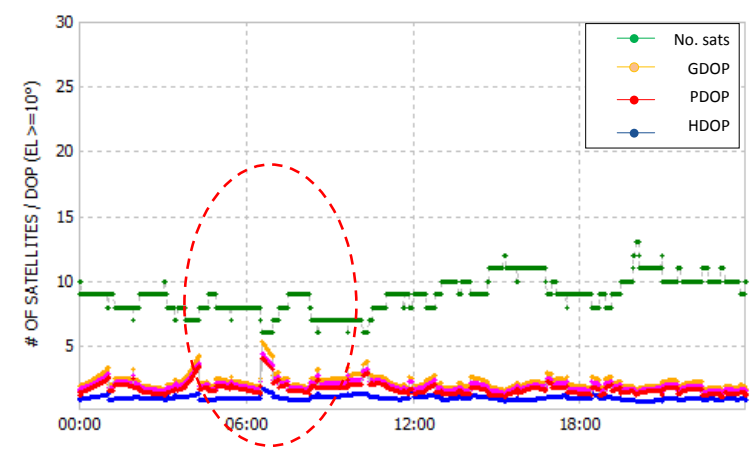

(b)

Figure 10. Satellite number and DOP values using a mask angle of $5^{\circ}(\mathrm{a})$ and $10^{\circ}$ (b) at Exmt

Figure 11 shows histograms of the number of stations that have ARAIM availability using elevation mask angles of $5^{\circ}$ and $10^{\circ}$ respectively. For the first case, it can be seen that most of 
the sites had ARAIM availability above 0.96. In comparison, the majority of sites had ARAIM availability between 0.9 and 0.96 when the elevation mask angle was raised to $10^{\circ}$, and only 7 stations can achieve availability above 0.96 .

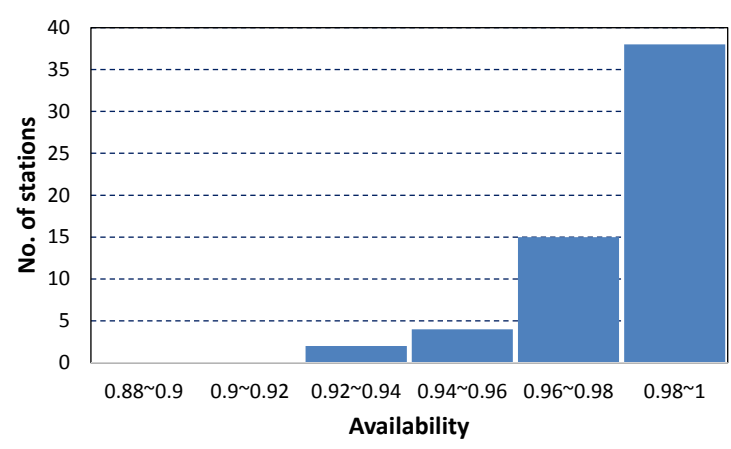

(a)

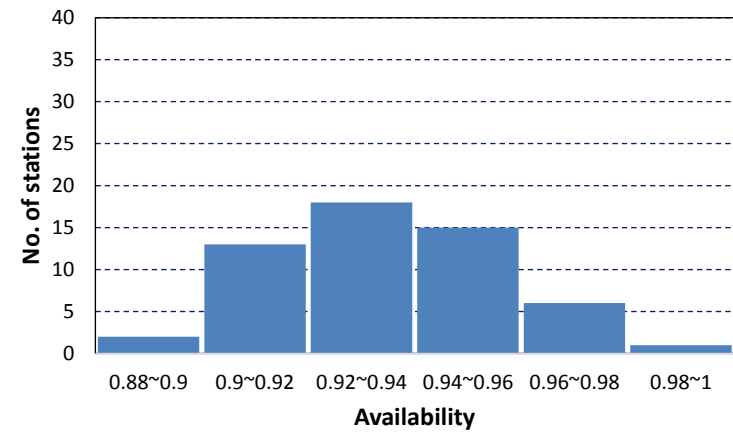

(b)

Figure 11. Frequency of ARAIM availability using elevation mask angle of $5^{\circ}$ (a) and $10^{\circ}(\mathrm{b})$

The above test results show that a full coverage of LPV-200 capability with an availability of $99 \%$ to $99.9 \%$ Australia wide cannot be met using GPS only in agreement with other studies that used simulated data. To achieve this objective, more satellites with a good geometry need to be observed. This can be accomplished by incorporating other GNSS constellations in ARAIM. In addition, it is undeniable that measurements from satellites with low elevation angles are affected by atmospheric refraction and multipath effects. However, as long as measurements of these satellites are properly weighted and do not have multiple faults, ARAIM can benefit from their inclusion. Nevertheless, favouring of $5^{\circ}$ over $10^{\circ}$ elevation mask-angle while may be used in practice should be carefully considered when studying ARAIM availability, where the latter mask angle is needed to account for small banking of aircraft.

\subsection{Sensitivity of ARAIM availability with changes in URE, bias int $_{\text {and bias }}$ acc}

Currently, the best values of the parameters URE, bias int $_{\text {and }}$ aias acc $_{\text {are not precisely }}$ known. They are proposed to be estimated in the future and provided through an ISM. Hence, the values used in the literature are assumed, derived from system performance. To characterize the impact of the above error model parameters on availability of ARAIM over Australia, the data at the 60 test sites were re-processed with values of the error parameters starting from a base value and gradually increasing in additional runs by a step of $20 \%$ of this base value. Thus, intervals of $0.05 \mathrm{~m}(0.25 \mathrm{~m} \times 20 \%)$ for $U R E, 0.1 \mathrm{~m}(0.5 \mathrm{~m} \times 20 \%)$ for bias $_{\text {int }}$ and $0.02 \mathrm{~m}(0.1 \mathrm{~m} \times 20 \%)$ for bias $_{\text {acc }}$ were used. The $20 \%$ interval was chosen such that it can suitably describe the change in trend and keep number of software runs reasonable. The change in ARAIM availability due to changes in these error parameters are plotted as line charts in the Figures 12 to 14. The first value of the $\mathrm{X}$ axis in each figure is set as the most common minimum value used in the literature. For a better demonstration of changes in ARAIM availability (denoted by the $\mathrm{Y}$ axis), a unified $\mathrm{Y}$ scale was not used in the Figures.

Figure 12 shows the impact when $U R E$ varies from $0.25 \mathrm{~m}$ to $0.8 \mathrm{~m}$. The decline in ARAIM availability with the increase in $U R E$ is very small, with an average slope of approximately $1.25 \%$. The change of availability due to changes in bias $s_{\text {int }}$, depicted in Figure 13 is also small, albeit significant, with almost a linear trend that has an average slope of $1.6 \%$. Moreover, Figure 14 shows a slight change in ARAIM availability due to increasing bias $_{\text {acc }}$ with almost a linear trend of an average slope of $0.63 \%$. This change is 
considered insignificant and is the least compared with the other parameters. The Figures 7 , 12-14 and their results demonstrate that $U R A$ is the parameter that affects the ARAIM capability most compared with the other three error model parameters, followed by bias int, $U R E$ and last bias ${ }_{a c c}$.

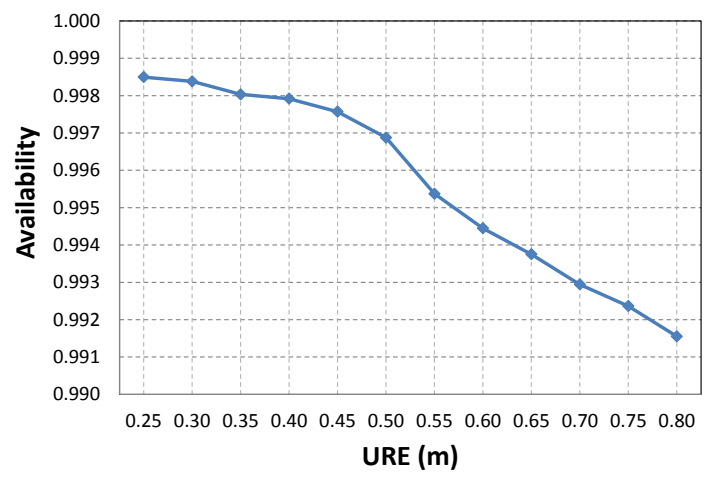

Figure 12. Change of ARAIM availability as a function of changing URE

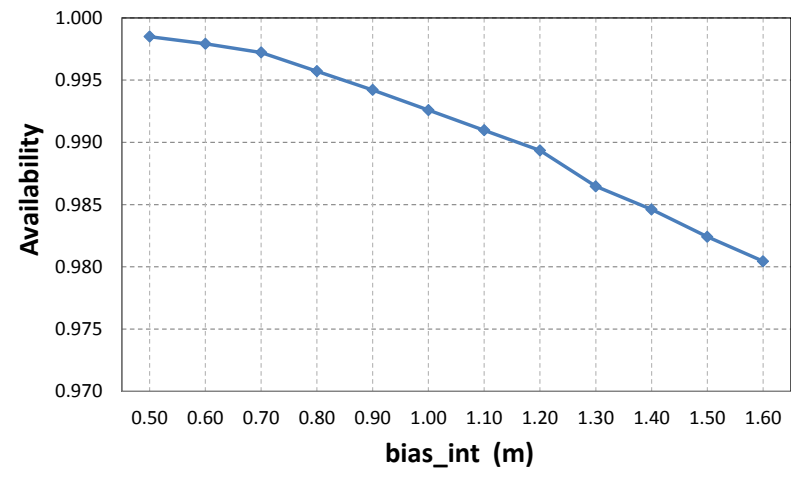

Figure 13. Change of ARAIM availability as a function of changing bias $s_{\text {int }}$

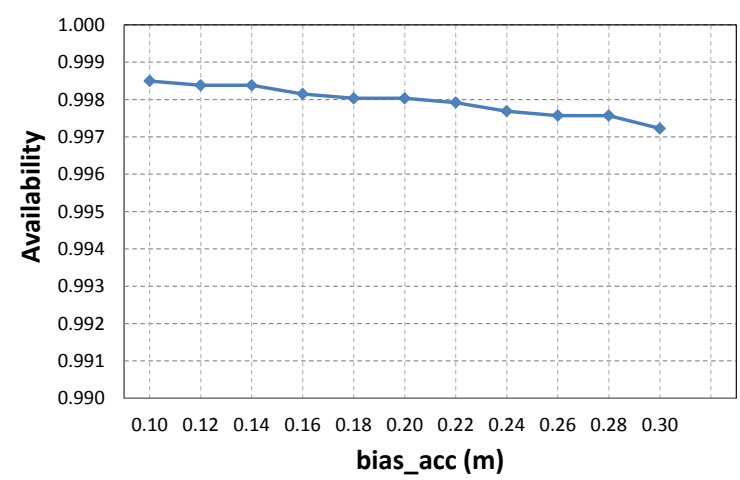

Figure 14. Change of ARAIM availability as a function of changing bias ${ }_{\text {acc }}$

\subsection{Integrity monitoring: $V P E<V P L<V A L$}

Results of the 60 sites of known positions during the testing period show that the computed $V P E$ using real data were always bounded by the $V P L$ and $V A L$, indicating neither misleading information (when $V P E>V P L$ ) nor hazardously misleading information (when $V P E>V A L)$. For example, at station CUT0 the $V P E / V P L$ ratio, depicted in Figure 15, was in general within \pm 0.2 . Although the collected data does not cover the designed probability 
$\operatorname{Pr}\{\mathrm{HMI}\}_{\mathrm{v}}$ of $10^{-7}$, which requires several years of data, it still gives a good indication about the expected performance of ARAIM.

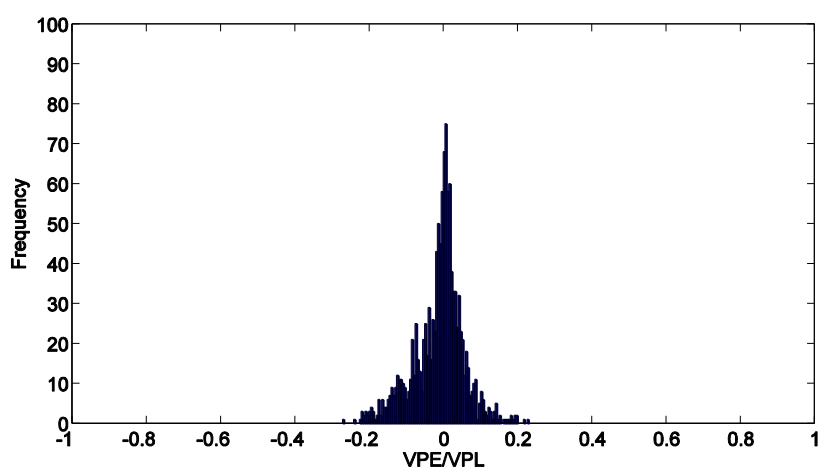

Figure 15. $V P E / V P L$ ratio using GPS at CUT0

\section{Improving ARAIM performance by integration of BeiDou and GPS}

The above results show that to achieve ARAIM availability above 99.5\% for LPV-200, more satellites with a good geometry need to be observed and this can be accomplished by incorporating other GNSS constellations along with GPS. The methodology of integrating GPS with other systems in ARAIM are discussed in GEAS (2010); Choi et al. (2012); Wu et al. (2013). In this study, results of integrating BeiDou with GPS are given as an example to demonstrate possible improvement in ARAIM availability when integrating GNSS. During time of testing, BeiDou had 14 operational satellites, which were all viewed in Australia. However, due to the limited number and distribution of the receivers capable of tracking BeiDou, demonstration of validation of ARAIM availability using GPS+BeiDou was carried out at two sites, in Eastern and Western Australia, as an example.

For BeiDou, rigorous basis for assumptions on fault-probabilities are not yet available. China Satellite Navigation Office has released the BeiDou Navigation Satellite System Open Service Performance Standard and signal ICD (CSNO 2013a,b) to provide information on how the system is going to be operated in the future. This would serve as a base for determining the appropriate degree of trust that can be placed in BeiDou. Furthermore, CSNO 2013a indicates that BeiDou SIS accuracy is $\leq 2.5 \mathrm{~m}$. BeiDou utilizes the same URA indexing system used in GPS, and according to (CSNO 2012), URA can be computed by using the formula $U R A=2^{I N / 2+1}$, where $N$ is the broadcast $U R A$ index. Furthermore, ElMowafy and $\mathrm{Hu}$ (2014) showed that BeiDou measurements gave precision close to that of GPS; therefore, we assumed that URE and nominal biases of BeiDou have the same values used for GPS. El-Mowafy (2013) suggested $P_{s a t, B D S}$ of $10^{-4}$, which was used in our study. This value was also assumed for $P_{\text {const }}$ of BeiDou.

The two test sites considered in this study were CUTO at Curtin University, Perth (Western Australia), and UNX3 at the University of New South Wales, Sydney (Eastern Australia). Both stations have accurately known positions that can be used for computation of the VPE. The data used were collected in March 2015 and was processed using broadcast $U R A$ values with an elevation mask angle $5^{\circ}$. The number of observed BeiDou satellites at any epoch ranged between 7 and 11 satellites at CUTO and between 6 and 9 satellites at UNX3. This is a notable number of satellites that can significantly add to ARAIM 
availability. Figure 16 illustrates a comparison between the use of GPS only (Figure 16.a) and when being integrated with BeiDou (Figure 16.b) at station CUT0. The figure shows the time series of VPL, VAL and the absolute values of $V P E$ on $1 / 3 / 2015$ as an example. Figure 17 illustrates the corresponding results at station UNX3. The figures show a substantial improvement to availability (i.e. $V P L<V A L$ ) when BeiDou was used with GPS compared with using GPS only as the VPL is significantly reduced. At CUT0, ARAIM availability has increased from $89.8 \%$ to $100 \%$ when augmenting GPS by BeiDou, and at UNX3 the corresponding availabilities increased from $92.7 \%$ to $100 \%$. The VPE values computed from the two systems measurements were also better than using GPS only as shown in the Figures 16 and 17. The average of the absolute values of $V P E$ has decreased from $2.42 \mathrm{~m}$ using GPS to $1.70 \mathrm{~m}$ using GPS+BeiDou at CUT0, and from $2.52 \mathrm{~m}$ to $1.74 \mathrm{~m}$ at UNX3. Again, the computed VPE for GPS+BeiDou were always bounded by the VPL and VAL. Figure 18 illustrates the $V P E / V P L$ ratio, which was in general lower than the corresponding values using only GPS measurements.

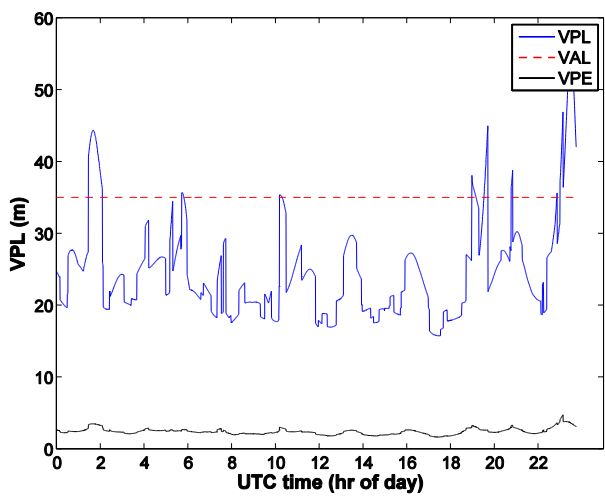

(a)

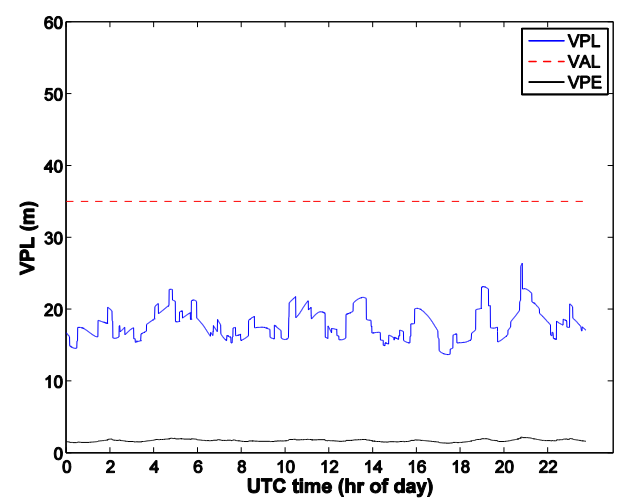

(b)

Figure 16. Intigrity monitoring using GPS only (a) and GPS+Beidou (b) at CUT0

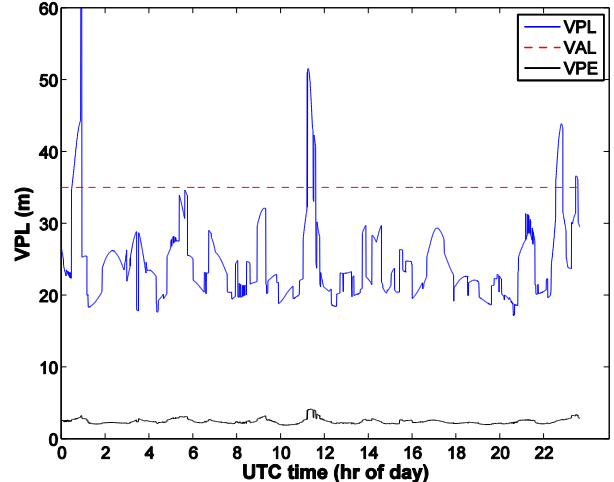

(a)

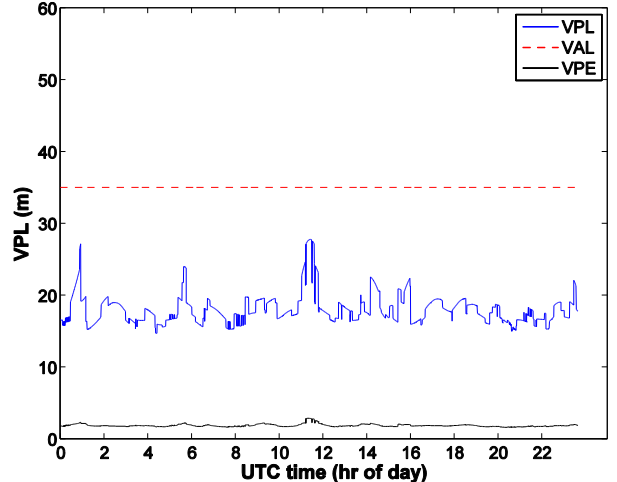

(b)

Figure 17. Intigrity monitoring using GPS only (a) and GPS+Beidou (b) at UNX3 


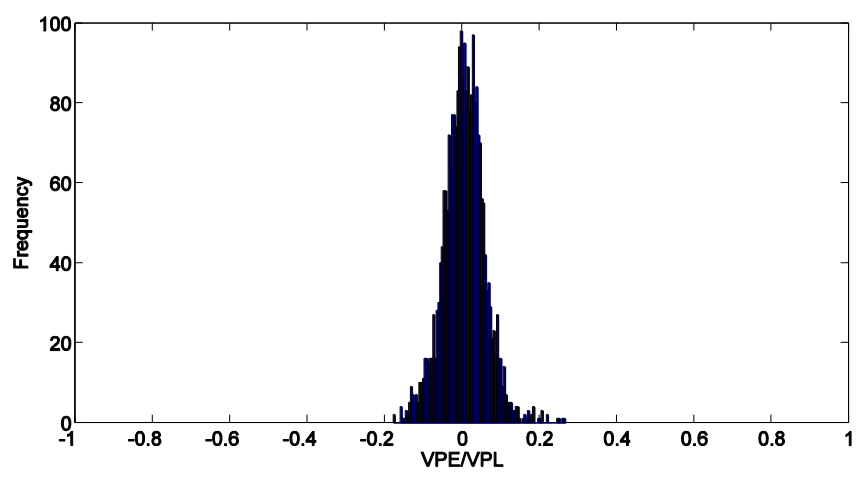

Figure 18. $V P E / V P L$ ratio using the GPS+BeiDou at CUT0

\section{Conclusion}

In this study, the availability of ARAIM for LPV-200 procedures using GPS is evaluated using real navigation files and GPS data of January 2014 collected at 60 CORS stations across Australia. In terms of the geographic distribution, the central area of Queensland had the highest ARAIM availability whereas Victoria and Tasmania had the poorest availability performance. Using an elevation mask angle of 5 degrees, ARAIM availability was $92.7 \%$ on average, which is not sufficient to support the use of the current GPS as the only navigation system for LPV-200 service and a combination of GPS and other GNSS constellations is needed. Test results at two test sites in Western and Eastern Australia, as an example, demonstrated the significant improvement in ARAIM availability when GPS was integrated with BeiDou, and showed the promising potential for achieving LPV-200 requirements.

ARAIM sensitivity analysis for the Australian data show that when the elevation mask angle changes from $10^{\circ}$ to $5^{\circ}$ the average ARAIM availability increased by about $5.2 \%$. However, $10^{\circ}$ mask angle might be needed in case of accounting for small banking of aircraft. The ARAIM availability with the current broadcast $U R A$ is $7.6 \%$ less than when an optimistic future $U R A$ value of $1 \mathrm{~m}$ is used. Furthermore, $U R A$ is numerically proven to be the error model parameter that affects the ARAIM availability most compared with other

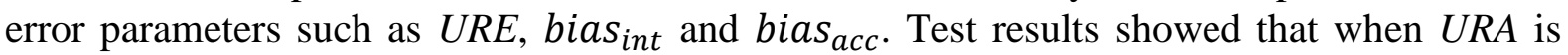
between $1 \mathrm{~m}$ and $2.4 \mathrm{~m}$, the availability decreases almost linearly with a slope of $2.5 \%$, and after $2.4 \mathrm{~m}$, a sharp decline in ARAIM availability can occur. The decline in availability with the increase in $U R E$ is very small, with an average slope of approximately $1.25 \%$. The change of availability due to changes in the bias int is small, with almost a linear trend that has an average slope of $1.6 \%$, whereas a slight change in ARAIM availability was experienced due to increasing bias $_{a c c}$ with almost a linear trend of an average slope of $0.63 \%$. These conclusions are only true for the data set studied and they might be indicative of the performance in other locations. 


\section{References}

Airservices Australia, 2014. GBAS implementation program. http://www.airservicesaustralia.com/ projects/ [Accessed 10 July 2015].

Blanch, J., Walter, T., and Enge, P., 2010. RAIM with Optimal Integrity and Continuity Allocations under Multiple Failures. IEEE Transactions on Aerospace and Electronic Systems, 46(3), 1235-1247.

Blanch, J., et al., 2012. Advanced RAIM User Algorithm Description: Integrity Support Message Processing, Fault Detection, Exclusion, and Protection Level Calculation. Proceedings of the 25th International Technical Meeting of The Satellite Division of the ION 2012, Nashville, September 2012, 2828-2849.

Blanch, J., et al., 2013. Critical Elements for a Multi-Constellation Advanced RAIM. Navigation, 60(1), 53-69.

Blanch, J., Walter, T., and Enge, P., 2014a. Exclusion for Advanced RAIM: Requirements and a Baseline Algorithm. Proceedings of the 2014 International Technical Meeting of The Institute of Navigation, San Diego, California, January 27 - 29, 2014, 99 - 107.

Blanch, J., Walter, T., and Enge, P., 2014b. Optimal Positioning for Advanced RAIM. Navigation, 60(4), 279-289.

Choi, M., et al., 2012. Evaluation of Multi-Constellation Advanced RAIM for Vertical Guidance using GPS and GLONASS Signals with Multiple Faults. Proceedings 25th Interntional Technical Meeting, ION, Nashville TN, Sept. 17-21, 2012, 884-892.

China Satellite Navigation Office (CSNO), 2012. BeiDou Navigation Satellite System Signal In Space Interface Control Document Open Service Signal B1 (Version 1.0), www.beidou.gov.cn., 2012. / [Accessed 10 July 2015].

China Satellite Navigation Office (CSNO), 2013a. BeiDou Navigation Satellite System Open Service Performance Standard (BDS-OS-PS-1.0), www.beidou.gov.cn., 2013. [Accessed 10 July 2015].

China Satellite Navigation Office (CSNO), 2013b. BeiDou Navigation Satellite System Signal in Space Interface Control Document Open Service Signal (BDS-OS-SIS-ICD-2.0)," www.beidou.gov.cn., 2013. [Accessed 10 July 2015].

El-Mowafy, A., 2013. RAIM for Vertical Guidance Using GPS and Beidou. Journal of Global Positioning System, 12(1), 28-37.

El-Mowafy, A., 2014a. GNSS Multi-frequency Receiver Single-Satellite Measurement Validation Method, GPS Solutions, 18, 553-561.

El-Mowafy, A., 2014b. ARAIM Using GPS, GLONASS and Beidou, Proceedings of the European Navigation Conference (ENC-GNSS) 2014, Rotterdam, Netherlands, April 14 - 17.

El-Mowafy, A. and Hu, C. 2014. Validation of Beidou Observations. Journal of Applied Geodesy, $8(2), 155-168$.

Ene, A., Blanch, J. and David, P.J., 2007. Fault detection and elimination for Galileo-GPS vertical guidance. Proceedings of the 2007 NTM of ION, San Diego, 22-24 Jan., 2007, 1244-1254.

EU-U.S. Cooperation on Satellite Navigation Working Group, 2012. C-ARAIM Technical Subgroup Milestone 1 Report. http://ec.europa.eu/enterprise/newsroom/cf /getdocument.cfm?doc_id=7793, [Accessed 10 July 2015].

EU-U.S. Cooperation on Satellite Navigation Working Group, 2015. C-ARAIM Technical Subgroup Milestone 2 Report, http://www.gps.gov/policy/cooperation/europe/2015/working-group-c/ARAIMmilestone-2-report.pd, [Accessed 10 July 2015].

GNSS Evolutionary Architecture Study Phase II Report (GEAS), 2010. http://www.faa.gov/about /office_org/headquarters_offices/ato/service_units/techops/navservices/gnss/library/documents/media /GEASPhaselI_Final.pdf. [Accessed 10 July 2015].

ICAO, Annex 10, 2009. GNSS standards and recommended practices (SARPs). Section 3.7, Appendix B, and Attachment D, Aeronautical Telecommunications, Vol. 1 (Radio Navigation Aids), Amendment 84.

IS-GPS-200H, 2013. Interface Specification, NAVSTAR GPS Space Segment/ Navigation User Interfaces, 24 Sept 2013, http://www.gps.gov/technical/icwg/IS-GPS-200H.pdf [Accessed 10 July 2015].

Ivanov, V. B., G.D. Gefan, O.A. Gorbachev (2011), Global empirical modelling of the Total Electron Content of the ionosphere for Satellite Radio Navigation Systems, Journal of Atmospheric and SolarTerrestrial Physics, 73,1703-1707. 
Jin, S.G., G. Occhipinti, and R. Jin (2015), GNSS ionospheric seismology: Recent observation evidences and characteristics, Earth-Sci. Rev., 147, 54-64, doi: 10.1016/j.earscirev.2015.05.003.

Jin, S.G., T. van Dam, and S. Wdowinski (2013), Observing and understanding the Earth system variations from space geodesy, $J$. Geodyn., 72, 1-10, doi: 10.1016/j.jog.2013.08.001. Joerger, M., and Pervan, B., 2014. Solution Separation and Chi-Squared ARAIM for Fault Detection and Exclusion, Proceedings of IEEE/ION PLANS 2014, Monterey, CA, May 2014, 294-307.

Joseph, A., Schnaufer, B., and Kazmierczak, J., 2014. Analysis of the Use of GPS+GLONASS for Aviation Applications, Proceedings of the $27^{\text {th }}$ International Technical Meeting of The ION Satellite Divison, Tampa, 8-12 Sept. 2014, 805-814.

Lee, Y. C., 1986. Analysis of Range and Position Comparison Methods as a Means to Provide GPS Integrity in the User Receiver. Proceedings of the 42nd Annual Meeting of The Institute of Navigation, Seattle, WA, 1-4.

Lee, Y., 2012. New Advanced RAIM with Improved Availability for Detecting Constellation-wide Faults Using Two Independent Constellations, Navigation, 60(1), 71-83.

Liu, Y., and Zhu, Y., 2014. Design and Performance Evaluation of Airspace-Ground Cooperative GPS/Beidou Dual-constellation RAIM Algorithm. Proceedings of the 2014 International Technical Meeting of The Institute of Navigation, San Diego, California, January 27 - 29, 2014, 127 - 136.

Lin, C.W., and Jan S.S., 2014. Algorithm and Configuration Availability Tool for Integrity Monitoring Test Bed. Proceedings of the 2014 International Technical Meeting of The Institute of Navigation, San Diego, California, January 27 - 29, 2014, 223 - 233.

Parkinson, B. W., and Axelrad, P., 1988. Autonomous GPS Integrity Monitoring Using the Pseudorange Residual. NAVIGATION, 35(2), 225-274.

Rippl, M., et al., 2014. ARAIM Operational Performance Tested in Flight. Proceedings of the 2014 International Technical Meeting of The Institute of Navigation, San Diego, January 2014, 601-615.

Rippl, M., Spletter, A., and Günter, C., 2011. Parametric Performance Study of Advanced Recievr Autonoums Integrity Monitoring (ARAIM) for CombinedGNSS Constellations. Proceedings of the International Technical Meeting of The ION, San Diego, California, 24-26 Jan. 2011, 285-295.

RTCA Special Committee 159, 2004. Minimum Aviation System Performance Standards for the Local Area Augmentation System (LAAS), DO-245, Appendix D.

Shively, C., 2009. Analysis of Specified and Hypothetical GPS IIIC Integrity for LPV-200 Operations, Publications of The MITRE Corporation, 1-12, http://www.mitre.org/sites/default/files/pdf/ 09_5396.pdf. [Accessed 10 July 2015].

Walter, T., et al., 2013. Incorporating GLONASS into Aviation RAIM Receivers. Proceedings of the 2013 International Technical Meeting of the ION, San Diego, CA, 27-29 Jan, 2013, 239-249.

Wu, Y., Wang, J., and Jiang, Y., 2013. Advanced receiver autonomous integrity monitoring (ARAIM) schemes with GNSS time offsets. Advances in Space Research, 52(1), 52 - 61. 